\title{
Аспекты культуры
}

Aspects of Culture

DOI: $10.25178 /$ nit.2019.1.13

\section{Семантика структурных элементов тувинского танца}

\author{
Чойган Х. Санчай \\ Тувинский государственный университет, Российская Федерация, \\ Мария С. Кухта \\ Томский политехнический университет, Российская Федерация
}
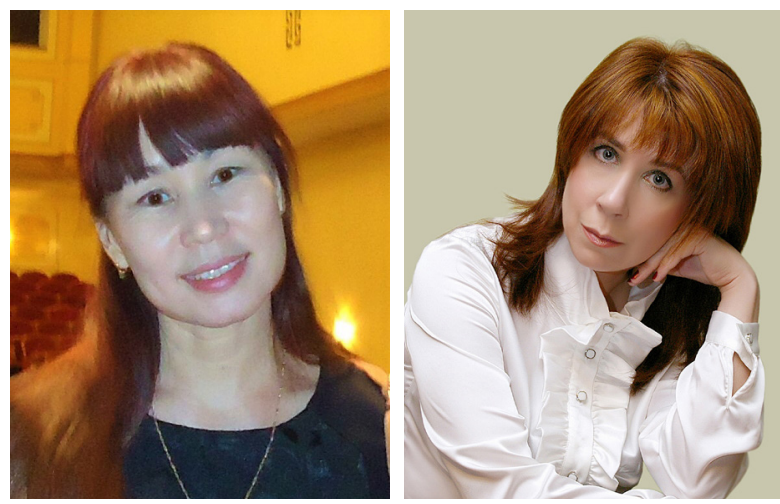

В статье представлен анализ танцевальных жестов и геометрии танца ритуально-обрядового наследия тувинцев. Танец понимается как интегральное явление культуры с ритуально-обрядовыми, бытовыми, трудовыми, игровые и др. движениями, положения, позы, жесты, пластика которых окрашена этнокультурными смыслами, связана с этнокультурной идентификацией. Структурно-семантический подход позволяет рассматривать танец как язык, выражаемый семантикой танцевального жеста. Источниковая база исследования: опубликованные работы по традиционным обрядам тувинцев и народов с родственной этнической культурой; материалы полевых исследований, проведенных в Монголии у этнических тувинцев в 2018 г.

Кинетическая традиция тувинцев «помнит» и «сохраняет» мифологические сюжеты. В тувинской традиционной пляске теп отмечаются движения (топтание) ногами, уподобляемых топоту сакральных животных (оленя, горного козла и т. д.). Обряд суг кежерде йөрээл содержит танцевальные движения с вырисовыванием ногами на земле геометрических фигур. Фигура из круговых вращений имеет связь с солярным культом, а семантика ног - с тотемной кинесикой.

В ритуальной пляске девиг - «танцуе орла»-интересны жесты руками. Взмахи рук бориов-силачей выражают полет птиц, облетающих просторы в благодарственном почтении Тенгри - небесного божества, созидателя. Жесты касания земли рукой - это выражение глубокого почтения матери-земле. Традиция круговых обходов и круговая композиция содержится в тувинском танце челер-ой.

Ключевые слова: тувинский танец; тувинцы; Тува; обряд; ритуал; язык тела; пляска; сакральный жест; сакральная геометрия; хуреш; танец орла

\footnotetext{
- Для циитирования:

Санчай Ч. Х., Кухта М. С. Семантика структурных элементов тувинского танца [Электронный ресурс] // Новые исследования Тувы. 2019, № 1. URL: https://nit.tuva.asia/nit/article/view/820 (дата обращения: дд.мм.гг.). DOI: 10.25178/nit.2019.1.13
}

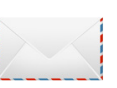

Санчай Чойган Херел-ооловна - соискатель кафедры философии Тувинского государственного университета, заслуженная артистка Республики Тыва. Адрес: 667000, Россия, г. Кызыл, ул. Ленина, д. 36. Тел.: +7 (394-22) -3-20-40; +7 (923) 542-65-76. Эл. адрес: choykasanchai@mail.ru. Научный руководитель - д-р филос. н. М. С. Кухта. ORCID: 0000-0002-6929-9050

Кухта Мария Сергеевна - доктор философских наук, профессор отделения материаловедения Томского политехнического университета. Адрес: 634050, Россия, г. Томск, пр. Ленина, д. 30. Тел.: +7 (913) 107-51-24. Эл. адрес: eukuh@mail.tomsknet.ru

Sanchay Choygan Kherel-oolovna, external postgraduate, Department of Philosophy, Tuvan State University; Honored Actress of the Republic of Tuva. Postal address: 36 Lenin St., Kyzyl, 667000 Russian Federation. Tel.: +7 (394-22) 3-2040;+7 (923) 542-65-76. E-mail: choykasanchai@mail.ru

Kukhta Maria Sergeevna, Doctor of Philosophy, Professor, Department of Material Studies, Tomsk Polytechnic University. Postal address: 30 Lenin Ave., Tomsk, 634050 Russia. Tel.: +7 (913) 107-51-24. E-mail: eukuh@mail.tomsknet.ru 


\title{
The semantics of the structural elements in Tuvan dance
}

\author{
Choigan H. Sanchai \\ Tuvan State University, Russian Federation, \\ Maria S. Kuchta \\ Tomsk Polytechnic University, Russian Federation
}

The article presents an analysis of the dance gestures and the geometry of dance as ritual and ceremonial heritage of Tuvans. Dance is understood as an integral cultural phenomenon with its own rituals and ceremonial, as well as motions, posture and gestures related to household, employment, games etc. All of these are filled with ethnic and cultural meanings and associated with a specific ethnocultural identity. The structural-semantic approach makes it possible to analyze dance as a language expressed by the semantics of its gestures. The study's source base includes published works on traditional ceremonies of Tuvans and peoples of related ethnic culture; and also materials of field studies conducted in Mongolia among ethnic Tuvans in 2018.

Kinetic traditions of Tuvan dance can be said to "remember" and "preserve" mythological subjects. The Tep traditional Tuvan dance features trampling movements akin to those made by sacred animals (deer, mountain goats, etc.). The rite of syg kezherde yereël contains dance moves with feet making geometric shapes on the ground. The dance figure of circular rotations has links with the solar cult, and the semantics of the legs - with the totem kinesics.

The Devig ritual dance - also known as the "dance of the eagle" - features interesting hand gestures. Swinging their hands like flapping birds' wings, wrestlers thank Tengri, the creator deity of the sky. Touching the ground with the hand is an expression of deep respect to mother earth. The tradition of circular movements and circular composition appears in the Tuvan dance of Cheler-Oi.

Keywords: Tuvan dance; Tuvans; Tuva; rite; ritual; body language; dance; sacred gesture; sacred geometry; khuresh; dance of the eagle

\section{Введение}

В условиях глобализации в культуре Тувы происходит дальнейший процесс трансформации культурно-исторических традиций, начавшийся еще в советское время (Кужугет, 2016; Самдан, 2018: 229; Данчай-оол, 2016: 36). Традиционные формы тувинской самобытности продолжают меняться и даже сливаться с формами массовой культуры (Харунова, 2010: Электр. ресурс). В этой связи активно обсуждаются вопросы реконструкции традиционных форм, их изучения и сохранения, в том числе тувинских танцев (Ондар, 2016).

Актуальность исследований обусловлена тем, что вопрос этнической специфики танцевальной культуры тувинцев долгое время не входил в поле внимания ученых. Хотя в последние годы появились первые работы, в том числе диссертационные исследования (Майны, 2014; Ондар, 2016). Работа Ш. Б. Майны посвящена в целом традиционным играм тувинцев, и тувинская хореография в контексте исследуемой темы рассматривается как пример (прием) для сценических постановок тувинских игр (Майны, 2014).

Труд И. О. Ондар на сегодня является единственной и специальной работой по тувинскому танцу (Ондар, 2016). Автор пишет, что к началу XX в. были зафиксированы лишь ритуально-обрядовые формы танца, эпизодическое описание которых приведены в записях исследователей и путешественников, посещавших Туву начиная с конца XIX в., но описание бытовых форм народных танцев не было обнаружено. Она пришла к выводу, что для становления 
традиционных танцевальных форм в Туве не было достаточных предпосылок, такое явление как танец не связано с народным бытом, а соотносится с ритуально-обрядовыми формами и функциями танца (там же: 3,78 ).

Существовал ли у тувинцев такой элемент культуры как танцы?

К. Сагды по этому поводу пишет: «...танца, как такового, в старой дореволюционной Туве не было. Было очень широко распространены песенные мелодии, по четкости ритмики они вполне могли бы быть танцевальными, но, видимо, сами условия жизни - в юртах, в чумах, в вечной тесноте - к танцам не располагали» (Сагды, 1973: 81). В записках путешественника и географа Г. Е. Грумм-Гржимайло, посетившего Туву в начале XX в., читаем: «Ударных инструментов, столь необходимых для ритма, у сойотов (одно из старых названий тувинцев) нет вовсе, и это следует, может быть, поставить в связь с отсутствием у них плясовой музыки и танцев в роде калмыцкого белеша или туркестанского седыра, требующих от исполнителей усиленных телодвижений» (Традиционная культура ..., 2003: 123). Русский режиссер И. Я. Исполнев, прибывший в 1940 г. из Советского Союза в числе специалистов для создания в Туве исполнительского искусства, в своем дневнике записал: «Совершенно отсутствуют танцы оказывается, народ не знает даже такого слова» (Кужугет, 2004: 206).

Между тем, искусство танца в Туве получило мощный толчок к развитию с приездом профессионального хореографа А. Шатина, приглашенного из Советского Союза в числе других специалистов в 1940-е годы. Сожно считать, что с этого момента начинается формирование сценического танца и зарождение танцевального искусства в Туве. Вместе с этим, постепенно подготавливается и почва для развития самодеятельной танцевальной культуры.

Этот факт не может не говорить о том, что основа для развития танца в культуре все же была. Об этом также писал в середине 1980-х годов А. Абайдулин, анализируя вопрос об истоках и перспективах тувинской хореографии: у тувинцев танец когда-то существовал, но «с годами исчез из народного быта» (Абайдулин, 1987: 3). Так, по его мнению, хорошо сохранились танцевальные элементы в народных праздниках и обрядах. Много элементов танца в играх «Тевек» (почекушки), «Аскак кадай» («Хромая старуха»). Недаром на их основе были созданы танцы. Танцевальных композиций много и в шаманских камланиях, и ламских мистериях. Абайдулин обращает внимание на динамику и танцевальный характер движений народного сказителя во время исполнения сказа: «то он покачивается в такт мелодии, то вскакивает на ноги и приплясывает» (там же). Он указывает на то, что сами песни, такие как «Хандагайты», «Декей-оо», «Дынгылдай» по ритму совершенно танцевальны и подчеркивает, что песня и инструментальная музыка - ближайшие спутники народного танца. Его интерес также вызывает девиг - своеобразный танец борцов, который автор считает народным мужским танцем. Это даже отражено в термине: в русско-тувинском словаре под редакцией профессора А. А. Пальмбаха слово «девиг» переводится как «пляска» (Тувинско-русский словарь, 1955: 138). При этом в других тюркских языках, напоминает Абайдулин, «в киргизском и татарском языках есть родственные слова дебип и тибеп, обозначающие удар ногой по земле - близкие понятию пляски» (Абайдулин, 1987: 3).

В целом, не вызывает сомнения то, что танец, являясь элементом культурной традиции любого народа, играет важную роль для сохранения традиционных ценностей. Связь танца и мировоззрения, как системы ценностей, прослеживается в культурной традиции танцевальных композиций. Это особенно хорошо видно, если рассматривать танцы с точки зрения анализа танцевальных жестов в их структурной композиции, поскольку именно в традиции ритуально-обрядового наследия сохранилась более поздняя форма танца.

В нашем понимании танец - это система, имеющая структуру и структурные элементы. Структурно-семантический метод представляет танец как язык, основанный на понимании семантики жестов. В связи с этим, целью данной статьи является структурно-семантический анализ тувинских танцев, основанных на ритуально-обрядовом наследии. Объектом иссле- 
дования являются танцевальные композиции в тувинской традиционной культуре, предметом исследования - элементы танцевальных композиций: танцевальные жесты, геометрия танца. Мы проанализируем каждый из структурных элементов танцевальной композиции с точки зрения их семантики, связи с системой религиозных верований.

Мы не рассматриваем здесь танцевальные элементы сценического танца, поскольку современная форма танца имеет отличные от традиционного наследия предпосылки зарождения и механизмы функционирования. Термин танец вслед за И. Ондар понимается нами как «интегральное явление культуры, в котором характерные для представителей тувинского этноса бытовые, трудовые, игровые, ритуально-обрядовые движения, положения, позы, жесты, пластические мотивы окрашены этнокультурными смыслами и связаны с этнокультурной идентификацией» (Ондар, 2016: 6).

Источниковой базой для нашего исследования выступили опубликованные научные работы по традиционным танцам тувинцев и народов с родственной этнической культурой (Дашиева, 2007; Стручкова, 2000; Султангареева, 2013; Самжид, 2014; Кыргыс, 2002). Кроме того, мы опираемся на материалы наших полевых исследований, проведенных нами в Монголии: г. Улан-Баторе в марте 2018 г. (опрошено 3 чел.), а также в Баян-Улгийском аймаке в июле 2018 г. (опрошено 10 чел.). Материалы хранятся в личном архиве у соавтора статьи Ч. Х. Санчай. Данное исследование продолжает работы авторов по теме тувинских танцев (Санчай, 2014, 2015; Sanchay, 2017; Санчай, Кухта, 2015, 2016, 2018).

\section{Язык танца}

Осмысление танцевальной культуры и роль танцев в традиционной культуре получило отражение в трудах Р. А. Султангареевой (Султангареева, 2013), Р. Самжид (Самжид, 2014), Л. Д. Дашиевой (Дашиева, 2007), Н. А. Стручковой (Стручкова, 2000), Hee Jung Lee (Hee Jung Lee, 2006: Электр. ресурс) и др.

Танец, как одна из моделей воспроизводства духовного потенциала этноса, представляет собой свод мифологических свидетельств и культурных знаний. И в этой связи для нас важны работы, посвященные семантическому аспекту мифологических мотивов, и их сопоставлению с архаической устной традицией в формировании ранних религий (Хомушку, 2013; Кухта, 2004b; Абаев, 2010; Кыргыс, 2002; Дэвлет Е., Дэвлет М., 2005; Фрейденберг, 1998; Воронцов, 2018; Маликов, 2012). Связь движения тела и культурной событийности отражается в возможности прочтения жестов в танцевальной традиции, в связи с чем необходимо исследование их семантики на основании работ Ф. Соссюра (Соссюр, 1977), Ю. М. Лотмана (Лотман, 1996).

Структурно-семантический подход позволяет рассматривать танец как язык, выражаемый семантикой танцевального жеста. В нашем исследовании жест трактуется как смысловая единица в структуре танца, которая, с одной стороны, участвует в формировании танцевальной геометрии, обеспечивающей диалог танцующего с предками и богами, а, с другой стороны, является самостоятельной смысловой константой. Символизм каждого жеста в структуре танцевального текста-высказывания позволяет исследовать специфику культурного наследия, не сводимого к воспроизводству обрядовых практик, обеспечивающих бытовые потребности, но обращает внимание исследователей на множество вертикальных и горизонтальных связей многомерного мира.

Язык тела - это очень древний, очень мудрый и уникальный инструмент, который понимается и как инструмент самовыражения, и как инструмент познания и общения. В жестах человека, в его реакциях заложена память многих поколений наших предков. Движение всегда сопутствовало жизнедеятельности человека и связано с работой первобытного сознания. Слово и мысль были равны действию. Жесты сопровождают ритуально-обрядовые действа. Обрядовое действо неотделимо от пляски и песни. Жест является элементом древней пляски. Так, по мнению Р. А. Султангареевой, танец является смысловым телодвижением. Древний 
человек каждый свой жест, движение корпуса регламентировал и оформлял в смыслодвижение (Султангареева, 2013). Таким образом, танец в обрядовой традиции вбирает в себя, отражает все его знаковые элементы. Элементы движений тела комбинируются в смыслонесущие значения ритуала.

Таким образом, семантический анализ подразумевает исследование языка танца, выделение смысловых доминант и семантических единиц, которыми являются жесты, приобретающие статус «значений». Мифологические основания культуры предполагают отражение идеи создания в каждом смысловом фрагменте. Жест, являясь самостоятельной единицей, несет в себе полноту знания о мире, «как артефакт, содержащий в себе весь мир, включая момент его создания» (Маликов, 2012: 22). Таким образом, отраженный и сохраненный в жесте миф выводит исследование к истоку сакральных (священных) истин, лежащих в основании любой культуры.

Для анализа танцевальных композиций нами выделены смысловые структурные элементы: танцевальный жест и геометрия танца. Танцевальные жесты в свою очередь различаются в пластике тела на жесты руками и движения ногами. В общепринятом понимании жест - это движение руками, головой, корпусом, а движения нижней части тела - это пластика ног. Так, в нашей статье мы будем использовать условный термин танцевальные жесты для обозначения элементов движений танца исполненные и ногами, и руками. Геометрия танца в нашей работе понимается нами как действие, в ходе которого воспроизводится геометрическая фигура. Это исполнение фигуры движением рук, ног, головой, корпусом, а также фигура, исполненная группой участников. То есть способы исполнения различают в одном случае пластическое телодвижением рук, ног и т. д. одного человека (в данном случае мы рассматриваем преимущественно жесты рук и движения ног), в другом - группу участников (к примеру, выстраивающихся вереницей) танцевально-ритуального действа, в результате которого прорисовывается общая фигура (здесь мы будем говорить о круге, вертикали и горизонтали).

\section{Танцевальный жест: семантика ног}

Для анализа характерных танцевальных жестов рассмотрим тувинскую традиционную пляску теп от слова тевер - ‘лягать, пинать ногой’ (Тувинско-русский словарь, 195: 389) и обряд переплывания реки суг кежерде йөрээл (суг - ‘вода'; кежер - ‘переходить', йөрээл - ‘благословение’ (Тувинско-русский словарь, 1955: 374, 220, 197)

Первоначально ритмическая сторона действа доминировала над формой. Сакральную сущность шага отмечают многие исследователи (Стручкова, 2000: 129-140). Характерная особенность пляски - это преимущественно исполнение плясовых элементов с лексикой в ногах без перемещений в пространстве. Топтание на месте в пляске маркируется как основное движение.

В тувинском языке сохранилось выражение чаза тевер, что означает 'хорошо сплясать', 'показать пляс'. Рассмотрим производные слова от тевер. В словаре под редакцией А. А. Пальмбаха слово тевер переводится как 1) лягать, пинать, бить ногой; 2) упираться ногами; 3) плясать. Слово тевиг переводится как 1) удар, толчок; 2) пляска. Слово тевиишкин переводится как «удар, толчок» (ногой) (Тувинско-русский словарь, 1955: 392). Еще два слова производные от mеn: тепкиленир -1) дрыгать ногами, брыкаться. Новые слова производные от теп: тепкииш - 1) ступенька, 2) педаль (там же 394). Слово «удар» в русско-тувинском языке переводится на тувинский язык как кагары, cozapы, шанчары, тевери. В значении «удар кулаком» слово тевер не используется, что любопытно, данное слово будет использоваться только в значении удара ногой бут-биле тевери (Русско-тувинский словарь, 1980: 600). Слово «пинать» переводится как тевер (там же: 387). Таким образом, слово тевер в значении «удар, толчок» используется только в значении удара ногой (Тувинско-русский словарь, 1955: 392). Существует выражение в тувинском языке с понятием плясать, к примеру: «Чаза теп көрээлем, че!», что по смыслу переводится как «Ну-ка, покажем молодецкую удаль, спляшем!» Подпрыгивания 
на месте с верчениями в обряде суг кежерде йорээл представляют собой элементы пляски. На сегодня вопрос существуют ли обрядовые переплясы в культуре тувинцев, а так же в культуре этических тувинцев Монголии остается открытым.

Как отмечают некоторые дансологи, семантика элементов нижней части предполагает отражение движения сакрального животного. В древнетюркском словаре отмечено, что тувинское слово теп имеет значение 'пляска' (Севортян, 1980: 195). Таким образом, сопоставимое с древнетюркским понятием теn - 'лягаться, брыкаться, топать' и тувинское men, mевер 'лягать, пинать, бить ногой' связано с древними зооморфными символами (Тувинско-русский словарь, 1955: 392). В казахском языке слово топыр обозначает стук конских копыт и громкого топота людей. В хакасском языке также теб от теп - стучание копытами, топание. В якутском тибий означает издавать дробный стук или плясать, дробно стуча. Это позволило сделать вывод, что кинесика ног была связана с мотивом магического топтания, в котором прослеживаются архаические практики психофизического воздействия ритма (Стручкова, 2000). Поэтому ‘топание ногами’ означает уподобление топоту сакральных животных (оленя, горного козла и т. д.). Топот, перебирание ногами, олицетворение сакральных животных, в котором придается особое значение движению ног в пляске, как динамической части тела, несущей смысловую нагрузку. Следовательно, тувинское слово men, mевер - 'пляска' выступает в значении движенческого подражания, в котором мифические действия божества с тотемическими чертами отражаются символической пластикой, выраженной жестом.

Традиционный обряд переплывания рек суг кежерде йөрээл, описанный исследователем тувинской музыки 3. К. Кыргыс (Кыргыс, 2002: 70), еще в недавнем прошлом имел функциональное бытование. Обряды, связанные с верой в способность человека воздействовать на людей и явления природы, возникли в древнем обществе как один из элементов шаманской мистерии. Тот, кому предстояло совершить обряд переплывания реки, должен был на берегу проделать движения в мелодико-ритмической форме. Участники обряда «вырисовывали ногами на земле геометрические фигуры, пытались научиться вертеться на одной ноге в обе стороны и, постукивая по железному предмету, в такт подпрыгивать» (Кыргыс, 2002: 70).

Поэтические тексты песен-кличей представляют собой многократное повторение слова хартыгай ('ястреб') и завершаются пением күүвей, или ку, или эй (там же). Нужно было, прежде всего, пробудить таинственные силы, которые могли бы помочь благополучной переправе, и сконцентрировать мысли участников обряда на движении плота. Исследователи отмечают, что физический эффект звука имеет сильное воздействие на человеческое тело (Элиаде, 2000). Эффективность обряда зависела от обусловленности силы звука, магическим многократным повторением күүвей - имени божества.

Таким образом, обряд переплывания рек суг кежерде йөрээл, представляет собой акт поклонения - сакральное действо, выражаемое в форме мифотворческого представления, в котором уже появились зачатки будущего танца. Обряд интересен с точки зрения жестов, выраженных в символическом значении. Пластика ног активна; выстраивается композиция из элементов с изображением геометрических фигур - круга на земле, которые дублируются вращениями то на одной, то на другой ноге и усиливаются ритмическими подпрыгиваниями. По-видимому, фигура из круговых вращений имеет связь с солярным культом, а семантика ног - с тотемной кинесикой.

Отметим, что семантика прорисованных фигур ногами на земле в обряде суг кежерде йөрээл, по своей природе телодвижения, обнаруживает типологические сходства с шаманскими плясками, издревле имевшими место в традициях различных народов. Например, в телодвижениях баксы - башкирского шамана запечатлены пранормы башкирского танца, имеющего функциональную суть, семантику и направленность (Султангареева, 2013: 11). В шаманских ритуалах большое значение имела ритуальная подстилка, предназначенная для жертвенных подношений и служившая местом, на котором совершали прошение. В Якутии во время ысыаха наступание на ритуальную подстилку ногой также вероятно было ритуальным 
жестом, олицетворением контакта, как и в шаманском камлании, белого шамана с божеством aйыbl (Стручкова, 2000: 104). Отметим, что шаманы в среде этнических тувинцев Монголии, до сих пор при камлании используют ритуальную подстилку ${ }^{1}$. Два мира божественный и земной (сакральный и профанный) соединены в этом символическом жесте: одной ногой шаман находился в «своем» мире, другой ногой - в «чужом».

\section{Танцевальный жест: семантика рук}

Традиционные верования на территории Саяно-Алтая представляют собой сложную систему религиозных воззрений, культов и обрядов. Все они были связаны между собой генетически. Так, промысловый культ связан с культами хозяев местности, а шаманизм, более поздняя форма традиционных верований, сохранил элементы дошаманской мифологии, обрядности и ритуалов. Эти формы религии служили не только отражением определенных условий жизни, они являлись выражением духовных потребностей, частью их культуры. В мифологических сюжетах повествуется о создании мира, его делении на уровни: Верхний мир, Средний мир, Нижний мир. Когда было сотворено вверху голубое небо, а внизу земля, между ними были сотворены сыны человеческие. В тувинских мифах прослеживается деление на два начала - Небо (мужское начало) - Земля (женское начало) (Хомушку, 2013).

Рассмотрим, каким образом кинетическая традиция тувинцев «помнит» и «сохраняет» мифологические

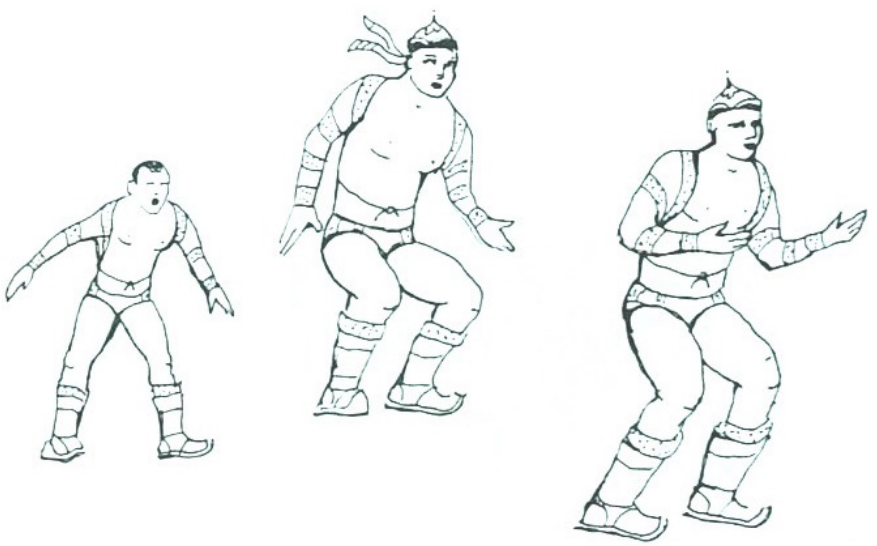

Рис. 1. Жесты похлопывания бедер в ритуальном танце девиг. Автор Шой Чурук, 2019 г.

Fig.1. Thigh-clapping in Devig ritual dance. By Shoi Churuk, 2019. сюжеты. Жест касания земли рукой зафиксирован в ритуальной пляске девиг - «танце орла» (Санчай, 2014: Электр. ресурс). Путешественники, посетившие Урянхайский край в конце XIX - начале XX в. пишут: «По окончании (соревнования хуреш. Ч. С., М. К.) победитель исполнял какой-то удивительный танец вдоль всего круга, шлепал при этом руками сперва о свои бедра, а затем о землю» (Традиционная культура тувинцев ... , 2003: 158). Во-первых, шлепки о землю и бедра выражают идею мощи ног борца (puc. 1), его способности удержаться на двух ногах в момент схватки с противником (по правилам тувинской борьбы считается проигрышем касание земли трех точек) (Майны, 2014: 19). Во-вторых, пляска девиг уже «потеряла» кинесику магического топтания, но касание земли выражает священную благодарность Матери-Земле. В-третьих, здесь, прослеживается традиция почитания неба древних тюрков ${ }^{2}$ (Скифо-хунно-тюркские ..., 2007), к которым относят и современных тувинцев. Ссылаясь на Л. Н. Гумилева, Н. В. Абаев утверждает, что термин «тюрк» переводится как «тэнгрианец», и как «сильный, подобно Небесному быку», и как «сильный» (Абаев, 2010: 27).

Взмахи рук борцов-силачей выражают полет птицы, облетающей кругом бескрайние просторы в благодарственном почтении Тенгри. В связи с этим заметим, что слово мөге - 'си-

${ }^{1}$ Так нам сообщил Дондорын Дарьчулуун, 1966 г. р., практикующий шаман в 8-ом поколении из рода көк багши, живущий в Улан-Баторе, уроженец сомона Баянт, Баян-Өлгийского аймака Монголии.

2 Древние тюрки почитали Вечное Синее Небо (Тенгри), называли себя голубыми тюрками и сформировали определенную систему поклонения Тенгри (Скифо-хунну ..., 2007: 97). 
лач, борец, богатырь, сильный' сопоставим со словом мөгеер - 'кланяться' (Тувинскорусский словарь, 1955: 285). Древние якуты называли танец словом, которое обозначалось от 'кланяюсь, молюсь'. Лейтмотивом поведения танцевального действа были поклоны. Мифологическая семантика пляски девиг теперь связана с образом посланника неба, героя (победителя).

B-четвертых, семантика рук исполнителя, в виде широко расправленных крыльев, выражает молитвенное обращение к божеству и одновременно выражает глубокое почтение матери-земле и небу-созидателю.

Структура ритуальной пляски состоит из системы жестов, каждый из которых является символом в пластической кинесике тела. Жест оранта - символ обращения и покло-

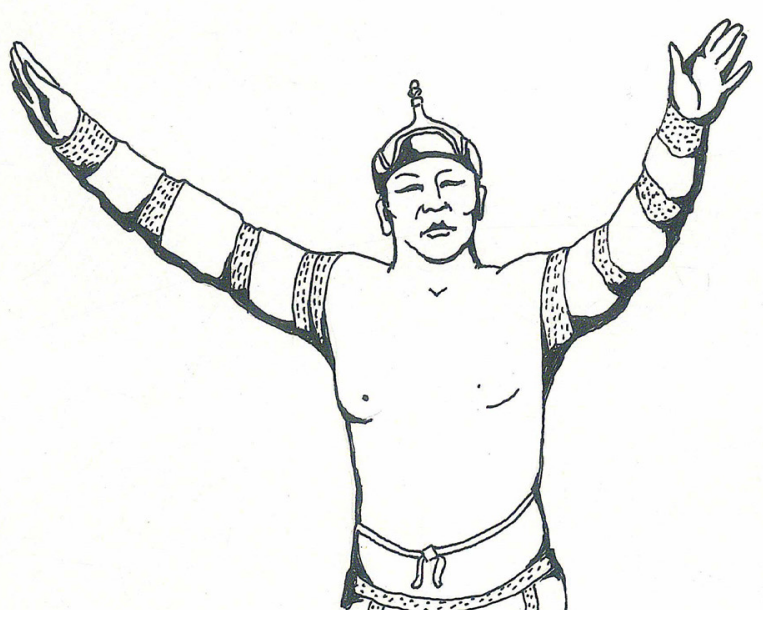

Рис. 2. Традиционный жест оранта - руки раскинуты как крылья птицы в полете. Автор Шой Чурук, 20192.

Fig. 2. Oranta, a traditional gesture, with hands outstretched, imitating bird's wings. By Shoi Churuk, 2019. нения божествам (рис. 2). Древний культо-
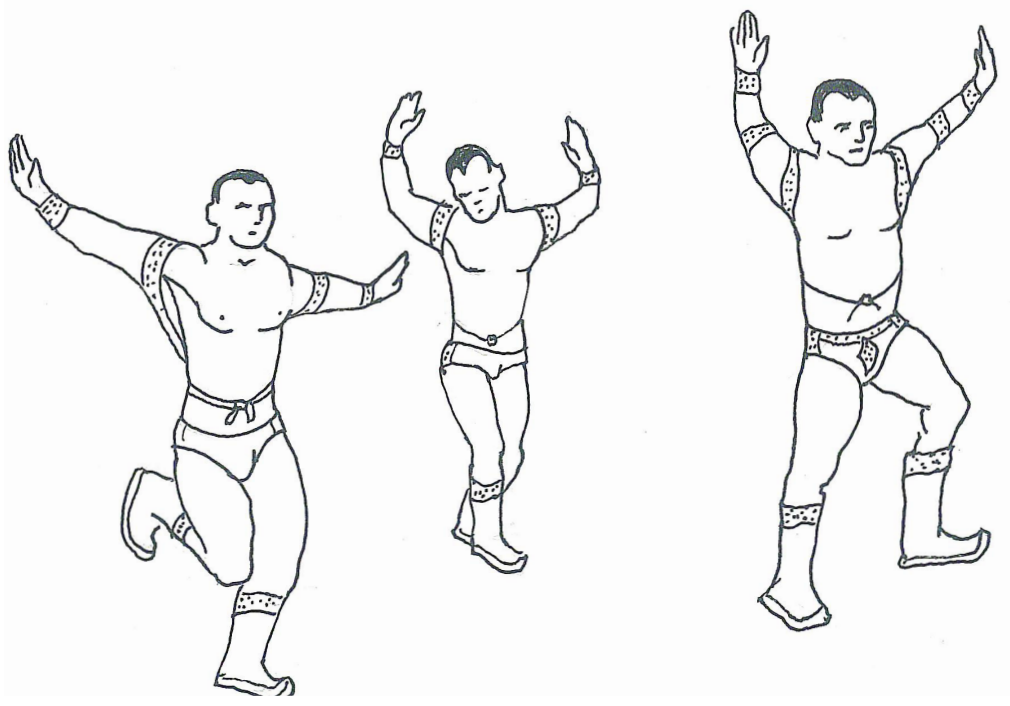

Pис. 3. Ритуальный танеи девиг. Автор Шой Чурук, 20192. Fig. 3 Devig ritual dance. By Shoi Churuk, 2019. вый жест имеет смысл просьбы с целью умилостивить духов (Дэвлет Е., Дэвлет М., 2005).

У тувинцев и ныне существует обряд чажыг (чалбарыг) - окропление молоком по кругу, по ходу солнца. Жест означает прошение снисхождения духов. В данном случае чалбарыг - молитвословие или благопожелание в форме действия, объектом обращения которого является небо (Санчай, Кухта, 2016). На наш взгляд, в ритуале девиг жест в виде распростертых крыльев - это оранта, знак-символ, выражающий обращенность к небу (рис. 3).

\section{Геометрия танща}

Традиция круговых обходов и круговая композиция появилась в период господства тотемных представлений. Перемещения в пространстве по кругу - функциональная особенность хоровода, коллективного культового действа. Круг является древней и основной формой хоровода. Формой композиции мы называем рисунок движения участников хороводного действа в пространстве. А образ в композиции пляски имеет символические черты, речь идет о солярном круге. Хоровод (кругом) обращен к небу, в чем мы усматриваем сакральную вертикаль, а плоскость земли как священная горизонталь - обозначается пляской.

Компаративный анализ танцев позволяет сделать вывод, что тувинский танец челер-ой, бурятский хороводный танец еохор (Дашиева, 2007), якутский хороводный танец осуохай (Стручкова, 2000), монгольский круговой танец дэвсэх (Самжид, 2014) имеют структурно-се- 
мантические параллели (Санчай, Кухта, 2016). Это позволяет отнести тувинский танец к типологически однородным танцам одного ареала культурной традиции.

Название танца челер-ой переводится как 'рысак' (челер - 'идти рысью') (Тувинско-русский словарь, 1955: 504). Еохор - общенациональное название хороводного танца бурятов и одна из разновидностей локального кругового танца. Слово еохор исследователи сравнивают с древнетюркским словом jugaru («вверх»), jugruk («быстрый, скорый»), jugur («бежать») (Дашиева, 2007: 26), в переводе означает рысак. В народе говорят - «пойдемте порысим», что значит, потанцуем. Таким образом, отметим схождения тувинского танца челер-ой с бурятским танцем еохор: 1) связь слов чүгұрүк, чүгұр - ‘быстрый, бежать' (Тувинско-русский словарь, 1955: $525)$, на наш взгляд, связан со словом еохор; 2) основная композиция танца челер-ой - круг; 4) у хоринских бурят существует парный хоровод хатарха; тувинский челер-ой сложился как парный круговой танец; 5) челер с тувинского языка означает ход коня рысью. На бурятском языке корень слова хатарха, хатар имеет два значения: 'рысь' (ход лошади) и 'танец'. Итак, тувинский танец челер-ой имеет все признаки хороводной композиции.

Вернемся к обряду суг кежерде йөрээл, в котором помимо элемента с вращениями (а именно вокруг своей оси), участник обряда как бы дублирует изображение круга на земле. Многократное повторение слова күүвей - называние почитаемого божества, на наш взгляд, является метафорой образа, пластика которого в данном обряде не визуализирована ${ }^{1}$. Функциональное значение ритуала как символическое действо выражается в акте поклонения культовому образу. Центральный образ невидим, но функционирует в форме метафоры. Образ называемого божества относится к системе культа неба, так обнаруживается вертикаль. Таким образом, композиция выстраивается таким образом, что происходит обозначение горизонтали семантикой ног и обозначена вертикаль многократным называнием образа - основным символом, к которому адресовано обращение.

К вопросу геометрии танца ритуальной пляски девиг отметим, что значение слова девир «может быть сопоставлен с тюрк. деn-, men- ‘лягаться, брыкаться, топтать' с тув. теn, означающим и 'танцевать, плясать'» (Татаринцев, 2002: 114). Это дает основание предполагать, что пляска теп получила функциональное продолжение в ритуальной пляске девиг. По мнению Э. В. Севортьяна, слово девир гл. 'плясать' имеет древнюю форму. Этимология слова девир разъясняется, как 'вращать крутить, вертеть', в котором значение кругового движения основное (Севортьян, 1980: 173). В данном случае значение кругового движения - это метафора небесного крылатого божества, которая проявлена в форме кругового обхода и одновременно обозначена вертикаль в форме объекта почитания.

\section{Заключение}

Анализ исследования тувинских танцев показывает их связь с древними мировоззренческими основаниями и сакральную кинесику танца тувинцев. На основе сформированного методологического каркаса мы можем выявить глубинную связь тувинского танцевального наследия с обрядово-ритуальными практиками. В структуре танца выделяется смысловая единица «жест», отражающая этнокультурную специфику и этническую кинесику танцевальной пластики. Очевидна связь жеста с тотемными представлениями и с мировоззренческими основаниями тувинской культуры.

Отголоски тотемных представлений нашли свое отражение в «подражательных» жестах танцев, имитирующих образы орла, лошади и т. д. Более поздние мировоззренческие концепции зафиксированы в сакральной геометрии танцев.

${ }^{1}$ Визуализация образа характерна для танцевальной пластики танца орла, танца быка, танца сокола и т. д. 


\section{Благодарности}

Благодарим за рисунки - иллюстрации к тексту, которые для нас любезно сделал член Союза художников России, председатель Союза художников Тувы Шой Улзайович Чурук.

\section{СПИСОК ЛИТЕРАТУРЫ}

Абайдулин, А. (1987) Тувинская хореография - истоки и перспективы. Творчество народа // Тувинская правда. 12 февраля. С. 3.

Абаев, Н. В. (2010) Тэнгрианство и ранние формы религии тюрко-моногольских народов Алтай-Байкалии. Кызыл : Изд-во ТывГУ. 131 с.

Вайнштейн, С. И. (1991) Мир кочевников Центра Азии. М. : Наука. 272 с.

Воронцов, В. А. (2018) Истоки искусства генерализованной трудовой теории антропосоциокультурогенеза. Казань : Центр инновационных технологий. 304 с.

Гумилев, Л. Н. (2002) Древние тюрки. 2-е изд. М.: Айрис-пресс. 504 с.

Данчай-оол, А. А. (2016) Трансформация культурно-исторической традиции в условиях глобализации // Актуальные проблемы исследования этноэкологических и этнокультурных традиций народов Саяно-Алтая, посвященной году гостеприимства в Республике Тыва : Материалы IV Международной научно-практической конференции молодых ученых, аспирантов и студентов / отв. ред. У. В. Ондар. Кызыл : Тувинский государственный университет. 227 с. С. 36-37.

Дашиева, Л. Д. (2007) Бурятский круговой танец ехор: историко-этнографический, ладовый, ритмический аспекты : дисс. ... канд. искусств. Новосибирск. 268 с.

Дэвлет, Е. Г., Дэвлет, М. А. (2005) Мифы в камне. М. : Алетейа. 471 с.

Кужугет, А. К. (2005) Культура и искусство ТНР // Ученые записки. Выпуск XX. 50 лет Ученым запискам. Вып. ХХ. Кызыл: Тувинский институт гуманитарных исследований. 420 с. C. 192-213.

Кужугет, А. К (2016) Духовная культура тувинцев: структура и трансформация. Красноярск : Офсет. 320 с.

Кухта, М. С. (2004а) Восприятие визуальной информации: философия процесса. Томск : Издательство Томского государственного педагогического университета. 202 с.

Кухта, М. С. (2004b) Полифония смыслов: постнеклассическая интерпретация пространства мифа // Полигнозис. № 2. С. 21-26.

Кыргыс, 3. К. (2002) Тувинское горловое пение. Новосибирск : Наука. 236 с.

Лотман, Ю. М. (1996) Внутри мыслящих миров. Человек - текст - семиосфера - история. М. : Языки русской культуры. 445 с.

Майны, Ш. Б. (2014) Народные игры в традиционной праздничной культуре тувинцев: историко-культурологический анализ : дисс. ... канд. культ. Кемерово. 186 с.

Маликов, У. В. (2012) Миф и танец. Опыт занимательной герменевтики / под ред. М. С. Кухта. М. : Канон ${ }^{+}$; РООИ «Реабилитация». 304 с.

Ондар, И. О. (2016) Генезис и трансформация тувинского танца в культуре Тувы : дисс.... канд. культ. Красноярск. 205 с.

Русско-тувинский словарь (1980) / под ред. Д. А. Монгуш. М. : Русский язык. 560 с.

Сагды, К. Ч. (1973) История возникновения тувинского театра. Кызыл : Тувинское книжное издательство. 140 с.

Самжид, Р. (2014) Хүн байгалийн шүтелцээ бай монгол бүжгийн гарал үүсэл, хөгжлийн ухаанд (Об истоках происхождения монгольского танца и его взаимосвязь с природой) // Танец как историко-культурное наследие монголоязычных народов : Материалы Международной 
научно-практической конференции, посвященной 75-летнему юбилею и 57-летию творческой деятельности П. Т. Надбитова / отв. ред. Н. Г. Очирова. Элиста : КИГИ РАН. 262 с. С 68-77. (На монг. яз.).

Самдан, 3. Б. (2018) Актуальные вопросы сохранения традиционной культуры тувинцев (на материале мифологических и фольклористических источников) // Современные этнические процессы и тенденции в Центральной Азии и Монголии : Международная научно-практическая конференция / отв. ред. У. В. Ондар. Кызыл : Тувинский государственный университет. 235 c. С. $229-233$.

Санчай, Ч. Х. (2014) «Танец орла» - духовно-художественное наследие тувинского народа [Электронный ресурс] // Новые исследования Тувы. № 1. URL: https://nit.tuva.asia/nit/article/ view/180 (дата обращения: 24.04.2018).

Санчай, Ч. Х. (2016) Культурные предпосылки возникновения тувинского хороводного танца «Челер-ой» [Электронный ресурс] // GAUDEAMUS IGITUR. Современные гуманитарные исследования. № 3. С. 52-56.

Санчай, Ч. Х., Кухта, М. С. (2016) Символическая пластика в танцевальной культуре тувинцев // Актуальные проблемы исследования этноэкологических и этнокультурных традиций народов Саяно-Алтая: материалы IV международной научно-практической конференции молодых ученых, аспирантов и студентов, посвященная Году гостеприимства в Республике Тыва / отв. ред. У. В. Ондар. Кызыл : Тувинский государственный университет. 227 с. С. 61-62.

Севортян, Э. В. (1980) Этимологический словарь тюркских языков. Общетюркские и межтюркские основы на букву «В», «Г», «Д». М. : Наука. 768 с.

Скифо-хунно-тюркские корни тувинской судьбы (2007) // Урянхай. Тыва дептер : Антология научной и просветительской мысли о древней тувинской земле и ее насельниках, об Урянхае - Танну-туве, урянхайцах - тувинцах, о древностях Тувы. [текст]: в 7 т. / составитель С. К. Шойгу. М. : Слово. 592 с. Т. 1: Древние племена Тувы и сопредельных территорий Центральной Азии (II тысячилетие до н. э. - конец XIX в.). 592 с. С. 21-120.

Соссюр, Ф. де. (1977) Труды по языкознанию / пер. с франц. под ред. А. А. Холодовича М. : Прогресс. 695 с.

Стручкова, Н. А. (2000) Семантика основных движений якутского хороводного танца осуохай : дисс. ... канд. ист. наук. Якутск. 188 с.

Султангареева, Р. А. (2013) Танцевальный фольклор башкир. Уфа : Гилем ; Башкирская энциклопедия. 128 с.

Татаринцев, Б. И. (2002) Этимологический словарь тувинского языка : в 4-х т. Новосибирск : Наука. Т. II. 389 с.

Традиционная культура тувинцев глазами иностранцев (конец XIX - начало XX века) (2003) / подготовка текстов, предисловие и комментарий А. К. Кужугет. Кызыл : Тувинское книжное издательство. 224 с.

Тувинско-русский словарь (1955) / под ред. А. А. Пальмбаха. М. : Государственное издательство иностранных и национальных словарей. 724 с.

Фрейденберг, О. М. (1998) Миф и литература древности. 2-е изд., перераб. и доп. М. : Восточная литература. 799 с.

Харунова, М. М.-Б. (2010) Проблемы возрождения национальной культуры в Туве в постсоветский период [Электронный ресурс] // Новые исследования Тувы. № 2. URL: https://nit.tuva. asia/nit/article/view/525 (дата обращения: 05.01.2019).

Элиаде, М. (2000) Шаманизм: Архаические техники экстаза. Киев : София. 480 с.

Хомушку, О. М. (2013) Религиозные традиции народов Саяно-Алтая как фактор формирования этноэкологической культуры // Мир науки, культуры, образование. № 6 (43). С. 489-492. 
Lee, Hee Jung (2006) Storytelling of the Korean traditional dance «The Hahoe Mask» using interactive multimedia. Thesis [Электронный ресурс] // Rochester Institute of Technology. URL:

https://scholarworks.rit.edu/cgi/viewcontent.cgi?referer=https://www.google.com/\&httpsredir $=1$ \&article $=7306 \&$ context=theses (дата обращения: 13.12.2018).

Sanchay, Ch. (2017) Semantics of Dance and Symbolic Plastic Movements in Tuvan Ceremonial System // Журнал Сибирского федерального университета. Серия: Гуманитарные науки. Т. 10, № 7. C. 1002-1006.

Дата поступления: 07.01.2019 г.

\section{REFERENCES}

Abaidulin, A. (1987) Tuvinskaia khoreografiia - istoki i perspektivy. Tvorchestvo naroda [Tuvan choreography, its origins and prospects. Creativity of the people]. Tuvinskaia pravda, 12 Februray, p. 3. (In Russ.).

Abaev, N. V. (2010) Tengrianstvo i rannie formy religii tiurko-monogol'skikh narodov Altai-Baikalii [Tengrianism and early forms of religion of the Turkic-Mongolian peoples of Altai-Baikal]. Kyzyl, TyvGU Publ. 131 p. (In Russ.).

Vainshtein, S. I. (1991) Mir kochevnikov Tsentra Azii [The world of nomads in the center of Asia]. Moscow, Nauka Publ. 272 p. (In Russ.).

Vorontsov, V. A. (2018) Istoki iskusstva generalizovannoi trudovoi teorii antroposotsiokul'turogeneza [The origins of the art of generalized labor theory of anthroposociocultural genesis]. Kazan', Tsentr innovatsionnykh tekhnologii. 304 p. (In Russ.).

Gumilev, L. N. (2002) Drevnie tiurki [Göktürks]. 2nd ed. Moscow, Airis-press. 504 p. (In Russ.).

Danchai-ool, A. A. (2016) Transformatsiia kul'turno-istoricheskoi traditsii v usloviiakh globalizatsii [Transformation of cultural and historical tradition in the context of globalization]. In: Aktual'nye problemy issledovaniia etnoekologicheskikh $i$ etnokul'turnykh traditsii narodov SaianoAltaia, posviashchennoi godu gostepriimstva $v$ Respublike Tyva [Urgent issues of research of ethnoecological and ethno-cultural traditions of the peoples of Sayano-Altai, devoted to the year of hospitality in the Republic of Tuva]: Proceedings of the 4th international research conference of young scientists, postgraduates and students / ed. by U. V. Ondar. Kyzyl, Tuvan State University. 227 p. Pp. 36-37. (In Russ.).

Dashieva, L. D. (2007) Buriatskii krugovoi tanets ekhor: istoriko-etnograficheskii, ladovyi, ritmicheskii aspekty [Buryat circular dance ekhor: historical-ethnographic, modal and rhythmic aspects]: Diss. ... Candidate of Arts. Novosibirsk. 268 p. (In Russ.).

Devlet, E. G. and Devlet, M. A. (2005) Mify v kamne [Myths in stone]. Moscow, Aleteia. 471 p. (In Russ.).

Kuzhuget, A. K. (2005) Kul'tura i iskusstvo TNR [Culture and art of the PRT]. Uchenye zapiski, vol. XX. Kyzyl, Tuvinskii institut gumanitarnykh issledovanii. 420 p. Pp. 192-213. (In Russ.).

Kuzhuget, A. K (2016) Dukhovnaia kul'tura tuvintsev: struktura i transformatsiia [Spiritual culture of Tuvans: structure and transformation]. Krasnoiarsk : Ofset. 320 p. (In Russ.).

Kukhta, M. S. (2004a) Vospriiatie vizual'noi informatsii: filosofiia protsessa [Perception of visual information: the philosophy of the process]. Tomsk, Izdatel'stvo Tomskogo gosudarstvennogo pedagogicheskogo universiteta. 202 p. (In Russ.).

Kukhta, M. S. (2004b) Polifoniia smyslov: postneklassicheskaia interpretatsiia prostranstva mifa [The polyphony of the senses: post-non-classical interpretation of the space of myth]. Polignozis, no. 2, pp. 21-26. (In Russ.).

Kyrgys, Z. K. (2002) Tuvinskoe gorlovoe penie [Tuvan throat singing]. Novosibirsk, Nauka. 236 p. (In Russ.). 
Lotman, Iu. M. (1996) Vnutri mysliashchikh mirov. Chelovek - tekst - semiosfera - istoriia [Inside thinking worlds. Man - text - semiosphere-history]. Moscow, Iazyki russkoi kul'tury. 445 p. (In Russ.).

Mainy, Sh. B. (2014) Narodnye igry $v$ traditsionnoi prazdnichnoi kul'ture tuvintsev: istorikokul'turologicheskii analiz [Traditional games in the traditional festive culture of the Tuvans: historicalcultural analysis]: Diss.... Candidate of Culture study. Kemerovo. 186 p. (In Russ.).

Malikov, U. V. (2012) Mif i tanets. Opyt zanimatel'noi germenevtiki [Myth and dance. An attempt at an entertaining hermeneutics] / ed. by M. S. Kukhta. Moscow, Kanon+ ; ROOI «Reabilitatsiia». 304 p. (In Russ.).

Ondar, I. O. (2016) Genezis i transformatsiia tuvinskogo tantsa v kul'ture Tuvy [Genesis and transformation of folk dance in the culture of Tuva]: Diss.... Candidate of Culture study. Krasnoiarsk. 205 p. (In Russ.).

Russko-tuvinskii slovar' [A Russian-Tuvan dictionary] (1980) / ed. by D. A. Mongush. Moscow, Russkii iazyk. 560 p. (In Russ.).

Sagdy, K. Ch. (1973) Istoriia vozniknoveniia tuvinskogo teatra [A history of the Tuvan theatre]. Kyzyl, The Tuva book publishing house. 140 p. (In Russ.).

Samzhid, R. (2014) Khün baigaliin shüteltsee bai mongol büzhgiin garal üüsel, khögzhliin ukhaand [On the origins of Mongolian dance and its relationship with nature]. In: Tanets kak istoriko-kul'turnoe nasledie mongoloiazychnykh narodov [Dance as a historical and cultural heritage of the Mongolian peoples] : Materials of the International research conference dedicated to the 75th anniversary of P. T. Nadbitov and 57th anniversary of his creative work / ed. by N. G. Ochirova. Elista, KIGI RAN. 262 p. Pp. 68-77. (In Mongolian).

Samdan, Z. B. (2018) Aktual'nye voprosy sokhraneniia traditsionnoi kul'tury tuvintsev (na materiale mifologicheskikh i fol'kloristicheskikh istochnikov) [Topical issues of preservation of traditional culture of Tuvans: mythological and folkloristic sources)]. In: Sovremennye etnicheskie protsessy i tendentsii v Tsentral'noi Azii i Mongolii [Contemporary ethnic processes and trends in Central Asia and Mongolia]: International research conference / ed. by U. V. Ondar. Kyzyl, Tuvan State University. 235 p. Pp. 229-233. (In Russ.).

Sanchai, Ch. Kh. (2014) «Tanets orla»-dukhovno-khudozhestvennoe nasledie tuvinskogo naroda [The "dance of the eagle" as spiritual and artistic heritage of Tuvan people]. The New Research of Tuva, no. 1 [online] Available at: https://nit.tuva.asia/nit/article/view/180 (access date: 24.04.2018). (In Russ.).

Sanchai, Ch. Kh. (2016) Kul'turnye predposylki vozniknoveniia tuvinskogo khorovodnogo tantsa «Cheler-oi» [The cultural background of the Tuva Celer-Oi round dance]. GAUDEAMUS IGITUR. Sovremennye gumanitarnye issledovaniia, no. 3, pp. 52-56. (In Russ.).

Sanchai, Ch. Kh. and Kukhta, M. S. (2016) Simvolicheskaia plastika v tantseval'noi kul'ture tuvintsev [Symbolic plastics in the dance culture of Tuvans]. In: Aktual'nye problemy issledovaniia etnoekologicheskikh $i$ etnokul'turnykh traditsii narodov Saiano-Altaia [Urgent issues of research in ethno-ecological and ethno-cultural traditions of the peoples of Sayano-Altai]: proceedings of the 4th international research conference of young scientists, postgraduates and students, dedicated to the year of hospitality in the Republic of Tuva / ed. by U. V. Ondar. Kyzyl, Tuvan State University. 227 p. Pp. 61-62. (In Russ.).

Sevortian, E. V. (1980) Etimologicheskii slovar' tiurkskikh iazykov. Obshchetiurkskie i mezhtiurkskie osnovy na bukvu «V», «G», «D» [Etymological dictionary of Turkic languages. Turkic and inter-Turkic roots, letters “ $B$ ”, “ $G$ ”, “ $D$ ”]. Moscow, Nauka. 768 p. (In Russ.).

Skifo-khunno-tiurkskie korni tuvinskoi sud'by [Scythian-Hun-Turkic roots of Tuvan destiny] (2007). In: Uriankhai. Tyva depter : Antologiia nauchnoi i prosvetitel'skoi mysli o drevnei tuvinskoi zemle i ee nasel'nikakh, ob Uriankhae - Tannu-tuve, uriankhaitsakh - tuvintsakh, o drevnostiakh Tuvy. [Uryankhai. Tuva depter: an anthology of scientific and educational thought about the ancient Tuvan 
land and its inhabitants, about Uryankhai - Tannu-Tuva, uryankhai - Tuvans, about the antiquities of Tuva]: in 7 vols. / comp. by S. K. Shoigu. Moscow, Slovo. 592 p. Vol. 1. Drevnie plemena Tuvy i sopredel'nykh territorii Tsentral'noi Azii (II tysiachiletie do n. e. - konets XIX v.) [Ancient tribes of Tuva and adjacent territories of Central Asia (second Millennium BC - the end of XIX century)]. 592 p. Pp. 21-120. (In Russ.).

Saussure, F. de. (1977) Trudy po iazykoznaniiu [Works in linguistics] / transl. from French, ed. by A. A. Kholodovich. Moscow, Progress. 695 p. (In Russ.).

Struchkova, N. A. (2000) Semantika osnovnykh dvizhenii iakutskogo khorovodnogo tantsa osuokhai [The semantics of the basic movements of the Yakut round dance osuokhai]: Diss. ... Candidate of History. Iakutsk. 188 p. (In Russ.).

Sultangareeva, R. A. (2013) Tantseval'nyi fol'klor bashkir [The dance folklore of the Bashkirs]. Ufa, Gilem; Bashkirskaia entsiklopediia. 128 p. (In Russ.).

Tatarintsev, B. I. (2002) Etimologicheskii slovar' tuvinskogo iazyka [An etymological dictionary of the Tuvan language]: in 4 vol. Novosibirsk, Nauka. Vol. II. 389 p. (In Russ.).

Traditsionnaia kul'tura tuvintsev glazami inostrantsev (konets XIX - nachalo XX veka) [Tuvan traditional culture through the eyes of foreigners (late 19th - early 20th century)] (2003) / preparation of texts, preface and commentary by A. K. Kuzhuget. Kyzyl, The Tuva book publishing house. 224 p. (In Russ.).

Tuvinsko-russkii slovar' [A Tuvan-Russian dictionary] (1955) / ed. by A. A. Pal'mbakh. Moscow, Gosudarstvennoe izdatel'stvo inostrannykh i natsional'nykh slovarei. 724 p. (In Russ.).

Freidenberg, O. M. (1998) Mif i literatura drevnosti [Myth and literature of antiquity]. 2nd ed. Moscow, Vostochnaia literatura. 799 p. (In Russ.).

Kharunova, M. M.-B. (2010) Problemy vozrozhdeniia natsional'noi kul'tury v Tuve v postsovetskii period [Problems of reviving ethnic culture in post-Soviet Tuva]. The New Research of Tuva, no. 2 [online] Available at: https://nit.tuva.asia/nit/article/view/525 (access date: 05.01.2019). (In Russ.).

Eliade, M. (2000) Shamanizm: Arkhaicheskie tekhniki ekstaza [Shamanism: Archaic techniques of ecstasy]. Kiev, Sofiia. 480 p. (In Russ.).

Khomushku, O. M. (2013) Religioznye traditsii narodov Saiano-Altaia kak faktor formirovaniia etnoekologicheskoi kul'tury [The religious traditions of the peoples of the Sayan-Altai Republic as a factor in the rise of ethno-ecological culture]. Mir nauki, kul'tury, obrazovanie, no. 6 (43), pp. 489-492. (In Russ.).

Lee, Hee Jung (2006) Storytelling of the Korean traditional dance «The Hahoe Mask» using interactive multimedia. Thesis. Rochester Institute of Technology [online] Available at: https:// scholarworks.rit.edu/cgi/viewcontent.cgi?referer=https://www.google.com/\&httpsredir=1 \&article $=7306 \&$ context $=$ theses (access date: 13.12.2018).

Sanchay, Ch. (2017) Semantics of Dance and Symbolic Plastic Movements in Tuvan Ceremonial System. Zhurnal Sibirskogo federal'nogo universiteta. Seriia: Gumanitarnye nauki, vol. 10, no. 7, pp. 1002-1006.

Submission date: 07.01.2019. 